\title{
Meio ambiente e a questão urbana
}

\section{Environment and the urban question}

\author{
Teresinha Maria GONÇALVES ${ }^{1}$
}

\section{RESUMO}

Este artigo discute a questão ambiental como um dos grandes fatores da sustentabilidade urbana associada a outros, como o acesso ao processo de desenvolvimento (intitulamento), à economia de comunicação, às políticas públicas e à cidadania. A reflexão parte da pesquisa realizada pela autora em Criciúma - SC, em 2001, que sustentou sua tese de doutorado em Meio Ambiente e Desenvolvimento.

Palavras-chave: sustentabilidade urbana, desenvolvimento sustentável, cidade e cidadania.

\begin{abstract}
This article examines the environmental question as one of the sustainable urban big factors and other ones as the access to the process of development (entitling), and the process of communication economy, public policeis and citizenship. The study started from the search accomplished by the author in CriciúmaSC, in 2001, and it supported her doctorate thesis about Environment and Development. Key-words: urban sustainable, development sustainable, city and citizenship.
\end{abstract}

\section{Introdução}

A problemática do meio ambiente e a questão urbana nos leva à reflexão sobre a cidade a partir do questionamento da noção de sustentabilidade como base para o conceito de cidades sustentáveis. Para tanto, utilizaremos a discussão de Lelé (s.d.). Durante os últimos anos, o conceito de desenvolvimento sustentável ou DS emergiu com a mais recente fase de propaganda do desenvolvimento. O conceito se tornou umparadigma que orientou organizações não-governamentais (ONGs) e governos, que o abraçaram e fizeram dele uma bandeira a ser desfraldada. Porém, segundo o autor citado, surgiu uma revisão na literatura que indica uma falta de consistência em sua interpretação. Mais importante, enquanto a natureza cerca o conceito, dá-se a ele a força política. Sua atual formulação pelo pensamento popular contém significantes fraquezas. Estas podem conduzir a contradições na formulação de políticas públicas. O conceito de desenvolvimento sustentável ficou universal, diz Lelé (s.d.). Tornou-se

\footnotetext{
1 Professora titular e pesquisadora da Universidade do Extremo Sul Catarinense - Unesc. Docente do Mestrado em Ciências Ambientais e dos cursos de Psicologia Enfermagem e Direito. Doutora em Meio Ambiente e Desenvolvimento Urbano - UFPR. Mestre em Psicologia Social - PUC/São Paulo.<E-mail: tmg@unesc.rctsc.br>
} 
uma "contra-senha" para agências internacionais, o jargão do planejador do desenvolvimento, o tema de conferências e documentos lidos e o "slogan" de ativistas, desenvolvimentistas e ambientalistas. Parece ter ganho o apoio, a base geral que outros conceitos, como o de ecodesenvolvimento, não tinham, sendo estabelecido para se tornar o paradigma dos anos 90. O conceito de DS está em perigo real de se tornar um clichê, a frase da moda, à qual todo mundo presta homenagem, mas que ninguém se preocupa em definir (LELÉ, s.d.). Tolba (apudLELÉ, s.d.) lamentou que o conceito de DS havia se tornado um artigo de fé, uma contrasenha. Um dos possíveis caminhos desse debate teórico indica a necessidade de discussão do desenvolvimento e da sustentabilidade, numa perspectiva que inclua, além dos argumentos da ecologia, os sociais, como a pobreza e a exclusão da maioria da humanidade no processo de desenvolvimento, e a crítica do sistema social que produz a brutal desigualdade nesse processo. Os argumentos dos economistas do livre mercado restringem o conceito de desenvolvimento a um processo meramente econômico. Sen (2000) vê o processo de desenvolvimento como expansão das liberdades substantivas. As liberdades humanas dependem de outros fatores além do meramente econômico. Esses fatores, que Sen (2000) denomina de determinantes e de disposições gerais e econômicas, são os direitos sociais, políticos e individuais pelo menos teoricamente garantidos no Estado de Direito. Porém, todo o debate não teria sentido se, dentro dele, não fossem discutidos os fatores estruturais dos sistemas sociais que produzem o desenvolvimento de forma desigual. No contexto, está a enorme desigualdade entre países ricos e pobres.

\section{Economia de comunicação}

O debate acerca da relação entre meio ambiente e a questão urbana nos remete ao conceito de sustentabilidade. Acselrad (1999) tem dado imp ortante contribuição ao debate sobre sustentabilidade urbana.

O que parece organizar analiticamente o discurso da "sustentabilidade urbana" seria sua distribuição em dois campos: de um lado, aquele que privilegia uma representação técnica das cidades pela articulação da noção de sustentabilidade urbana aos "modos de gestão dos fluxos de energia e materiais associados ao crescimento urbano"; de outro, aquele que define a insustentabilidade das cidades pela queda da produtividade dos investimentos urbanos, ou seja, pela incapacidade destes últimos acompanharem o ritmo de crescimento das demandas sociais, o que coloca em jogo, conseqüentemente, o espaço urbano como território político (ACSELRAD, 1999, p. 79).

O espaço pode ser contextualizado no processo de globalização da sociedade e da economia. Isso ocasiona a mundialização do espaço geográfico, dando-lhe novo significado. Com as necessidades do processo produtivo, são criadas hierarquias de utilização do espaço; por isso, há uma reorganização das funções entre as diferentes frações do território (sANTOS, 1997). Esse fato implica pensar a gestão ambiental no contexto urbano associada "à gestão dos ecossistemas e à produção dos fundamentos racionais da organização do território" (ACSELRAD, 1999, p. 84).

A questão nos faz pensar: a cidade, como espaço de qualidade de vida, serve para questionar as bases técnicas do urbano. O desenvolvimento puramente tecnológico, ligado ao desenvolvimento econômico, que não leva em conta o desenvolvimento social e cultural, tem produzido uma desigualdade geradora de conflitos sociais e políticos (MALETZeuX, 2001).

A corrente ideológica, representada pelo neoliberalismo e concretizada pela globalização da economia, tem produzido, segundo Maletzeux (2001), desenvolvimentos tecnológico e financeiro estupendos dos países localizados nos arquipélagos formados pelos pólos tecnológicos, interligados por uma rede que exerce a dominação no mundo.

Esses pólos tecnológicos, também chamados pólos de negócios internacionais ou de mercados globais, além de concentrar riqueza e poder, alteram a paisagem urbana. $\mathrm{O}$ poder está nesses centros de interesses arquitetonicamente representados. Escritórios de arquitetos famosos se colocam em concorrência para efetivar esse processo de rede. São famosos os arquitetos que construíram torres, como as torres gêmeas do World Trade Center, em Nova York.

Esses pólos, além da arquitetura arrojada, têm sofisticadas decorações, incluindo jardins, lagos, cinema, teatro, obras de arte, com a preocupação de deixar uma imagem limpa, sadia, bonita e, portanto, agradável ao lugar. $\mathrm{O}$ ator mais ativo desse processo é o capital internacional, contro lador das torres e de seus conteúdos. Essas são construídas por um conjunto de atores chamados de investidores, construtores e utilizadores do capital internacional. 
Se, à primeira vista, para a maioria do mundo, esses pólos podem parecer "ilhas de fantasia", uma coisa artificial, na verdade não o são, pois comandam, atualmente, a economia mundial, ditam normas e estão gerando, segundo, Maletzeux (2001), a chamada Economia de Comunicação. Sua principal característica consiste em ser lugar de comunicação e a realizam em todos os sentidos possíveis.

Ao lado dessa economia de comunicação, que é emergente, está a economia de produção, em franca decadência nos países dos pólos. Segundo Maletzeux (2001), a desindustrialização em países como: França, Holanda, Bélgica, Estados Unidos e Japão é um processo em ascensão. Como conseqüência, ocorrem grandes transformações sociais, econômicas e espaciais nesses países. O terceiro mund onão fica fora desse processo. Levam adiante a Economia de Produção para atender os países dos pólos, ao mesmo tempo em que consomem a alta tecnologia de comunicação aí produzida.

Com a economia da comunicação, as cidades sofrem uma transformação espacial, principalmente pela revitalização dos velhos centros decadentes e valorização de áreas de chamamento turístico. Os países que não fazem parte do clube dos países ricos, como o Brasil, sofrem a interferência dessa economia emergente nos países centrais.

O principal setor da economia em Criciúma é a indústria. Mas, de alguma forma, está ligada à economia de comunicação, quer pelo consumo de tecnologia, quer pelo fornecimento de produtos como material cerâmico.

Atualmente, em Criciúma, como em outras cidades do país, há um “clamor” por geração de empregos. Um dos entrevistados dessa pesquisa culpa os robôs e a tecnologia pela diminuição dos postos de trabalhos. O atual prefeito afirmou, em sua campanha, que geraria 10.000 empregos em sua gestão. Esse objetivo poderá ser alcançado ou não, buscando uma nova estratégia seguidora de outra perspectiva diferente da economia dos pólos denegócios internacionais. A comunidade da cidade de Criciúma, assim como toda a região carbonífera, com seus recursos materiais, imateriais e humanos, poderá servir de base para esse empreendimento.

\section{Cidade e cidadania}

Como espaço de legitimação das políticas urbanas, a cidade tem sustentabilidade nas condições de legitimação de tais políticas. Godard (1996) chega a falar da viabilidade política do crescimento urbano, ou seja, das condições de construção da base material das cidades, considerando que a insustentabilidade exprime a incapacidade de as políticas urbanas adaptarem a oferta de serviços urbanos à quantidade e à qualidade das demandas sociais, provocando, assim, um desequilíbrio entre as necessidades da população e as formas de satisfazê-las.

Na Região Carbonífera, a problemática está bastante colocada pelo fato de haver, no processo de exclusão social, um espaço destinado à pobreza: as áreas cobertas por rejeitos do carvão. Pode aparentemente ser paradoxal,mas as outras áreas ocupadas pela pobreza são as de preservação ambiental. Isto é exemplo de crescimento urbano que não está associado a investimentos de infra-estrutura e à oferta de serviços urbanos.

Sebastião Neto Campos² fala do início da urbanização da cidade e da região carbonífera, dizendo que o carvão aflorava em pouca profundidade e, onde isso ocorria, abria-se uma mina e fazia-se uma vila operária de casinhas de madeira, não havendo nenhum cuidado com a poluição. Então, a cidade ficou rodeada com pilhas de rejeitos jogados fora. Hoje, esses pontos estão dentro do perímetro urbano da cidade de Criciúma. Essa pirita dos amontoados de rejeitos poluiu todos os mananciais de água disponíveis para o consumo humano. Conta ele que "se um animal de pequeno porte bebesse essa água de cor alaranjada, poluída pela pirita, morria em pouco tempo".

Em decorrência da queima natural do carvão, o ar tornou-se "muito cheiroso", com ácido sulfúrico, o "cheiro de ovo podre". Em conseqüência disso, morria uma criança recém-nascida e menor de um ano a quase toda hora. Quando morria alguém, o sino da igreja batia para avisar a comunidade. Então, era um badalar constante do sino e aquelas fileiras de caixõezinhos saíam das vilas, perto das bocas das minas, iam para a igreja e, a seguir, as crianças eram enterradas.

Criciúma cresceu no bojo dessa fatalidade. Como foi uma cidade que praticamente nasceu do industrialismo, não houve nenhuma preocupação com a infra-estrutura urbana. Ao contrário, a atividade mineradora destruiu os recursos naturais, deixando a cidade e seu entorno quase inabitáveis para os seres humanos. Juntamente com a morte das crianças, ocorriam as mortes de muitos mineiros jovens,

2 Ex-minerador de Criciúma, depoimento a esta pesquisa em 2001. 
por falta de segurança nas minas, deixando muitas "viúvas do carvão". Essa situação só melhorou com a mecanização das minas e a aplicação das leis trabalhistas.

Atualmente, Criciúma ainda carece de infra-estrutura urbana. Uma cidade com 170.322 habitantes (IBGE, 2000) tem apenas $2 \%$ de esgotamento sanitário. Só recentemente, em 1999, segundo informações da Companhia de Desenvolvimento Econômico e Planejamento Urbano de Criciúma (Codepla), a prefeitura elaborou o plano diretor e o código de postura do município que são instrumentos essenciais para o planejamento urbano.

A falta de investimentos, como podemos observar no exemplo, repercute sob a forma de segmentação socioterritorial entre populações atendidas e não atendidas por tais serviços (ACSELRAD, 1999). O impacto material dessa política é questionado em função do desperdício de meios e da concentração socioterritorial dos benefícios. Por isso, a desigualdade social, no acesso aos serviços urbanos, é utilizada para questionar a legitimidade das políticas urbanas.

Perante esse quadro, torna-se necessário resgatar a cidade como espaço de qualidade de vida com base nos modelos da cidadania, bem como fazer a reconstituição da legitimidade das políticas urbanas com base nos modelos de eficiência e de eqüidade. Pode-se falar de sustentabilidade urbana não só relacionada às cidades sustentáveis, mas também às saudáveis, entendendo que uma envolve a outra.

Além das questões estruturais, a noção de cidades saudáveis acarreta a implementação de políticas de saúde, baseadas na universalização, integração, descentralização, unificação e a participação, conforme modelo SUS e modelo Sigal. Tais modelos requerem ultrapassar a noção de saúde, situada no campo individual, trabalhando sob uma perspectiva de saúde coletiva e reconhecendo a importância do aspecto ecológico em epidemiologia e no estudo da saúde de populações.

Em todos os momentos de nossa experiência vital tanto como indivíduos como coletivos, apresentamos um perfil de saúde-doença. Saúde e doença são expressões da vida, do "modo de levar a vida", como disse Canguilhem. Sentimo-nos doentes quando os problemas de saúde/ doença limitam a realização de nossos projetos e/ou coletivos. Sentimo-nos sãos quando os problemas de saúde/doença não limitam esta realização (BARATA, 1997, p. 62).

\section{Cidades saudáveis}

Segundo Duhl e Hancock (apudrivera, 1999), cidade saudável é aquela que coloca em prática, de modo contínuo, a melhoria de seu meio ambiente físico-social, utilizando todos os recursos de sua comunidade.

Nos países pobres e nos chamados em desenvolvimento como o Brasil, a maioria da população vive em situação de miséria, a exemplo dos trabalhadores rurais semterra, dos moradores de rua de São Paulo, Rio de Janeiro e outras grandes cidades. O crescimento dessas populações implica o crescimento do sofrimento humano.

Dessa forma, a deterioração dos sistemas naturais em áreas pobres é sintoma e causa de miséria, pois, na luta pela sobrevivência, a população de baixa renda não se preocupa com tendências ambientais globais (ECKHOLM, 1982). Perguntados sobre o que entendiam de meio ambiente, os moradores do bairro Renascer/Mina Quatro, em Criciúma, conceituaram meio ambiente de forma diferente da academia.

\section{Considerações finais}

O processo de desenvolvimento em Criciúma não difere do perfil do Brasil, ou seja, é um processo excludente. Existe, em Criciúma, um segmento social, representado por empresários e pequena parcela de profissionais liberais, que goza das liberdades substantivas, na perspectiva de Sen (2000). Por outro lado, a periferia da cidade é habitada por uma população não intitulada.

João Paulo Teixeira, em sua narrativa sobre o bairro Renascer/Mina Quatro, coloca com propriedade essa questão do não intitulamento da população de Criciúma que mora na periferia da cidade.

Uma comunidade inteira, comunidade que foi colocada em cima de lixão né. Aí se pergunta, até que ponto foi feito algum tipo de análise, alguma investigação, alguma pesquisa que indicasse a possibilidade da construção ou surgimento de uma comunidade em cima de um lixão né, sem que esse tenha sido preparado, trabalhado, obedecendo algumas técnicas mínimas necessárias. Para que as pessoas que viessem morar aqui como estão morando né, não sentisse tanto os efeitos dessa situação de degradação, antes mina, depois mais tarde lixão, e aí eu fico me perguntando, como se sente um morador ou uma comunidade que diante de áreas boas para se mo- 
rar são colocadas em cima de um lixão. Se partisse do meu sentimento eu me sentiria muito inferiorizado, me sentiria menos do que os outros, porque como que alguns podem morar em áreas que eles chamam de nobres e a outros fica reservado essa situação, essa situação de convivência dioturna com essa vergonha. Essa vergonha, com que é o que a gente está vendo nesse momento que é esse valo né, esse esgoto a céu aberto, esse cheiro é o cheiro de uma água envenenada né, uma água completamente morta né, essa água com certeza já foi uma fonte, quem sabe de alimento para algumas pessoas. ${ }^{3}$

O não-intitulamento priva as pessoas das liberdades substantivas. Com a privação das liberdades, no processo de desenvolvimento, fica complicado falar de preservação ambiental. Por isso, a discussão sobre meio ambiente e a degradação socioambiental urbana necessariamente passa pelo processo e modelo de desenvolvimento adotado.

Situada em um contexto ecologicamente relevante, dada a problemática ambiental que a envolve, Criciúma, cidade pólo da região carbonífera, estimula, nos meios acadêmicos regionais e em determinados segmentos da sociedade local, as discussões sobre a problemática do meio ambiente e do desenvolvimento.

O conflito socioambiental de Criciúma representa um conflito mais amplo que atualmente permeia o mundo: como preservar o ambiente natural e o social, as cidades, principalmente, e, ao mesmo tempo, promover o desenvolvimento econômico?

Eckensberger (2001) diz que a poluição ambiental é conseqüência de decisões e ações humanas. Por isso, toda análise de questões ambientais deve, necessariamente, lidar com aspectos descritivos e normativos. A descrição de problemas ambientais como o do carvão, por exemplo, bem como as normas da gestão ambiental, fazem uso de conhecimentos técnicos e científicos. Estes conhecimentos, segundo o autor, norteiam as decisões que os agentes da gestão ambiental, incorporados de poder político, tomam em relação aos problemas de meio ambiente.

\section{REFERÊNCIAS}

ACSELRAD, H. Discursos da sustentabilidade urbana. In: R.B. Estudos Urbanos e Regionais, [s.1.:s.n.], 1999.

BARATA, R.B. Condições de vida e situação de saúde. Rio de Janeiro: Abrasco, 1997.

CAMPOS, Sebastião N. Depoimento. Criciúma, 2001.

CODEPLAC (Companhia de Desenvolvimento Econômico e Planejamento Urbano de Criciúma) 2001.

ECKENSBERGER, Lutz H. Juízos morais no contexto de orientações de valores econômicos e ecológicos - o caso de uma usina de força abastecida a carvão. Frankfurt/Alemanha: Instituto Alemão para Pesquisa Educacional Internacional. In: TASSARA, Eda T. Panoramas interdisciplinares para uma psicologia ambiental do urbano. Tradução de: Maria Cecília Coelho (Org.). São Paulo: Educ/Fapesp, 2001. p. 141-186.

ECKHOLM, E. P. Down to earth, environment an human needs. New York: WW Norton, cap. I e II, 1982.

GODARD, O. Le development durable et le dévenir des villes, bonnes intentions et fausses bonnes idées. Paris: [s.n.], 1996.
IBGE (Instituto Brasileiro de Geografia e Estatística), 2000.

LELÉ, Sharachchandra M. Desenvolvimento sustentável: uma revisão crítica. [s.n.t.].

MALETZIEUX, Jacques. Economia de comunicação e organização do espaço. Curitiba, 2001. Tese (Doutorado em Meio Ambiente e Desenvolvimento) - Universidade Federal do Paraná

RIVERA, F. J. U. Agir comunicativo e planejamento social: uma crítica ao enfoque estratégico. Rio de Janeiro: Fiocruz, 1995.

SANTOS, M. Metamorfoses do espaço habitado. São Paulo: Hucitec, 1997.

SEN, Amartya. Desenvolvimento como liberdade. São Paulo: Companhia das Letras, 2000.

SIGAL, S. Elements for a new health strategy in third world contries. Paris: Cired, 1979.

TEIXEIRA, João Paulo. Depoimento. Criciúma, 2001.

3 João Paulo Teixeira, ambientalista. Narrativa realizada no bairro Renascer/Mina Quatro, 06 jan. 2001. 